Supplement of The Cryosphere, 9, 2311-2321, 2015

http://www.the-cryosphere.net/9/2311/2015/

doi:10.5194/tc-9-2311-2015-supplement

(C) Author(s) 2015. CC Attribution 3.0 License.

(c) (i)

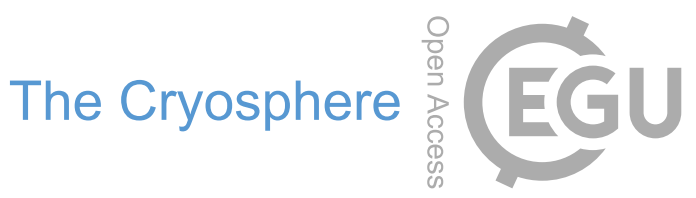

Supplement of

\title{
Evaluation of the CMIP5 models in the aim of regional modelling of the Antarctic surface mass balance
}

\section{Agosta et al.}

Correspondence to: C. Agosta (cecile.agosta@gmail.com)

The copyright of individual parts of the supplement might differ from the CC-BY 3.0 licence. 

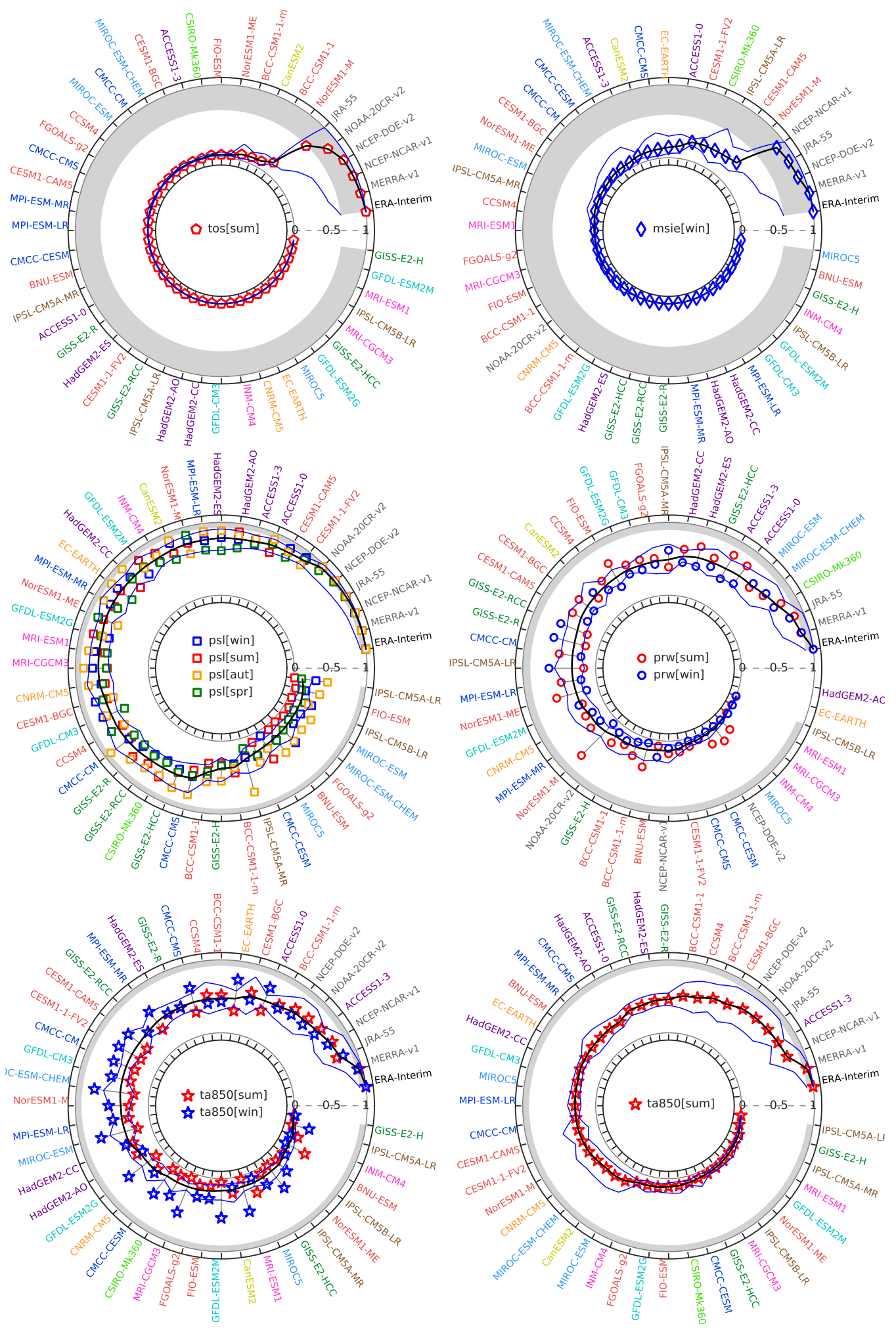

Figure S1: CPI scores, computed as $\exp \left(-\mathrm{CPI}^{2} / 2\right)$, range from 1 (best, external circle) to 0 (nul probability of belonging to the ERA-Interim distribution, internal circle). Models are ranked by CPI scores for each variable: summer sea surface temperature, winter meridional sea-ice extent, annual sea-level pressure, summer/winter precipitable water, summer/winter $850 \mathrm{hPa}$ air temperature, and summer $850 \mathrm{hPa}$ air temperature. Markers are for seasonal CPI scores and solid black line is for combined CPI scores. Blue lines are upper and lower bounds for the combined score taking into account multi-decadal variabilities of seasonal components. The grey crown width is the combination of 90th percentiles of CMIP5 GCMs multi-decal variabilities. Models with obvious similarities in code or produced by the same institution are marked with the same color (clusters), following Knutti et al. (2013). 

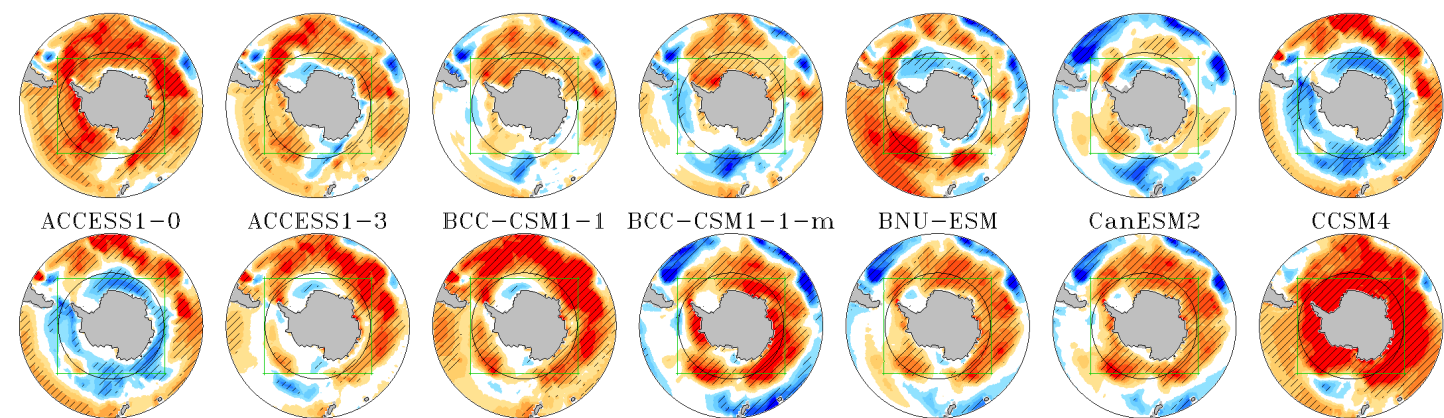

CESM1-BGC
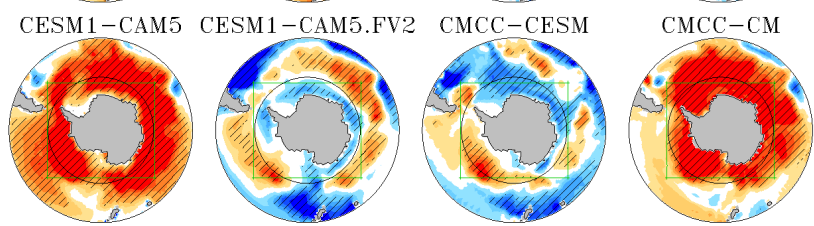

CMCC-CMS

CNRM-CM5
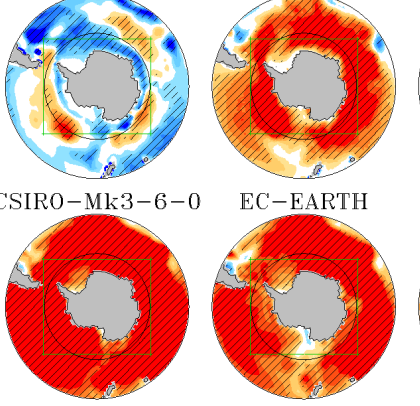

FGOALS - g2
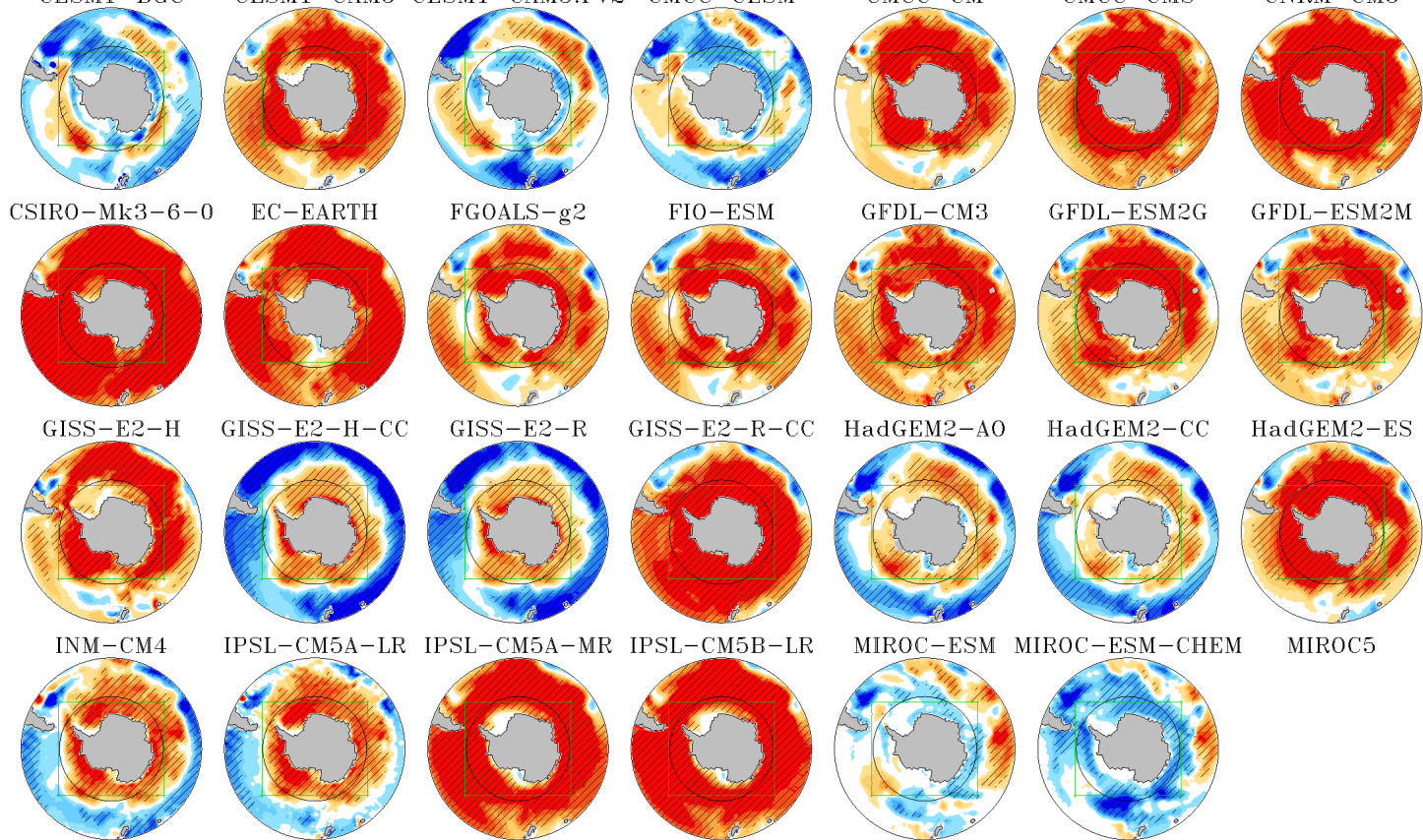

HadGEM2-ES

MPI-ESM-LR

MPI-ESM-M

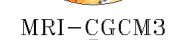

MRI-ESM 1
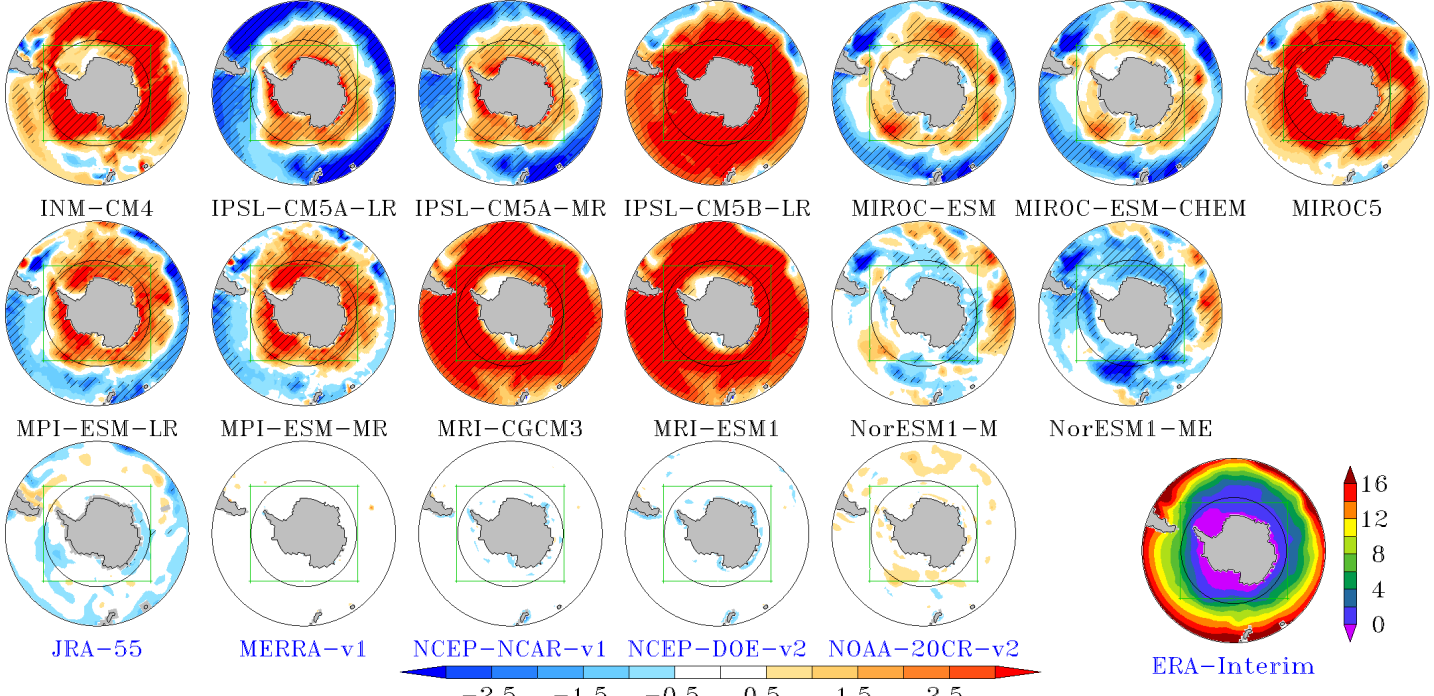

NorESM1-ME

Summer surface ocean temperature error in respect to ERA-INTERIM $1980-2004\left({ }^{\circ} \mathrm{C}\right)$

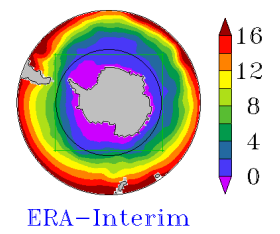

Figure S2: Same as Fig. 1 but for summer sea surface temperature $\left(\right.$ in $\left.{ }^{\circ} \mathrm{C}\right)$. 


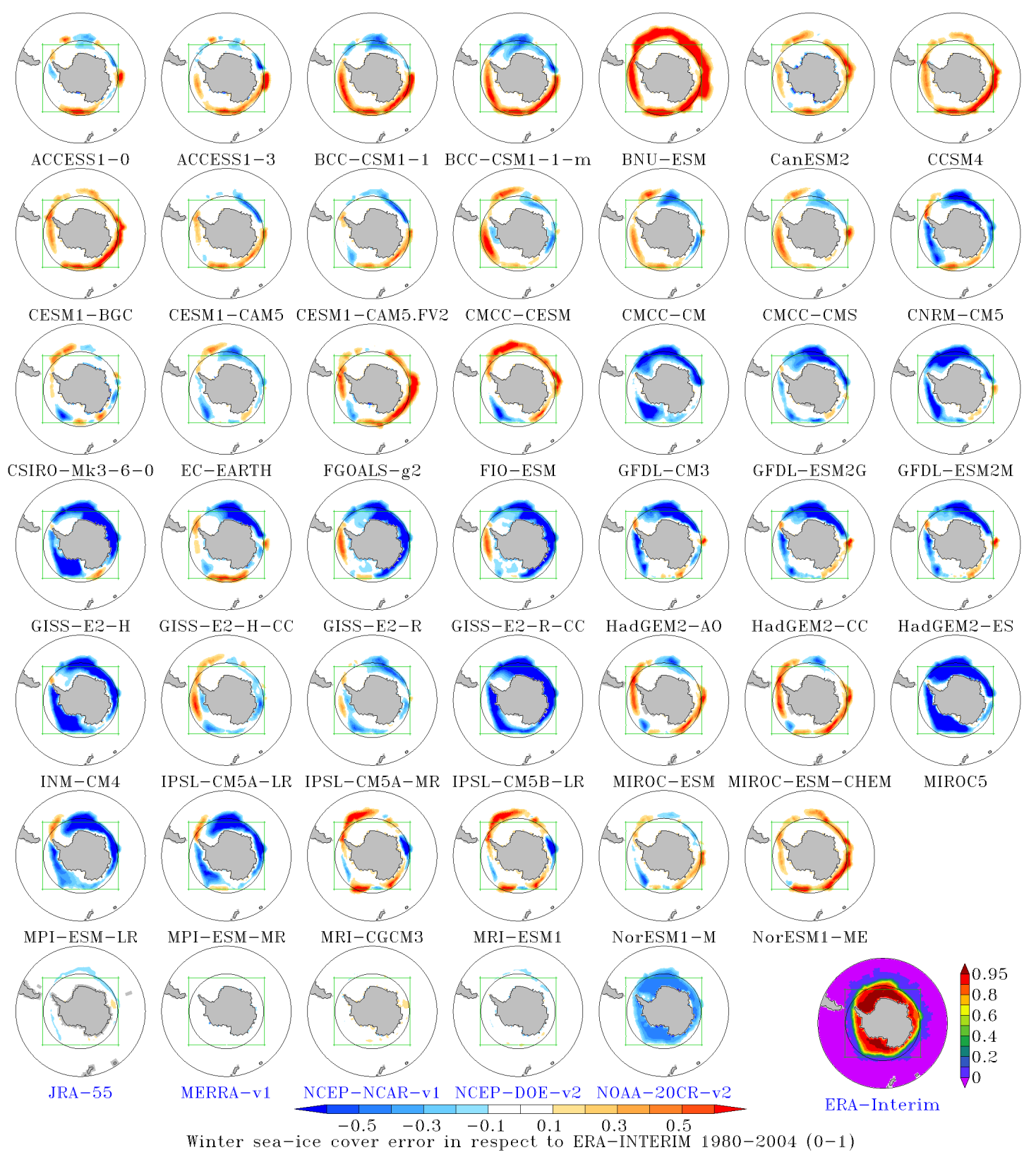

Figure S3: Same as Fig. 1 but for winter sea-ice concentration. 

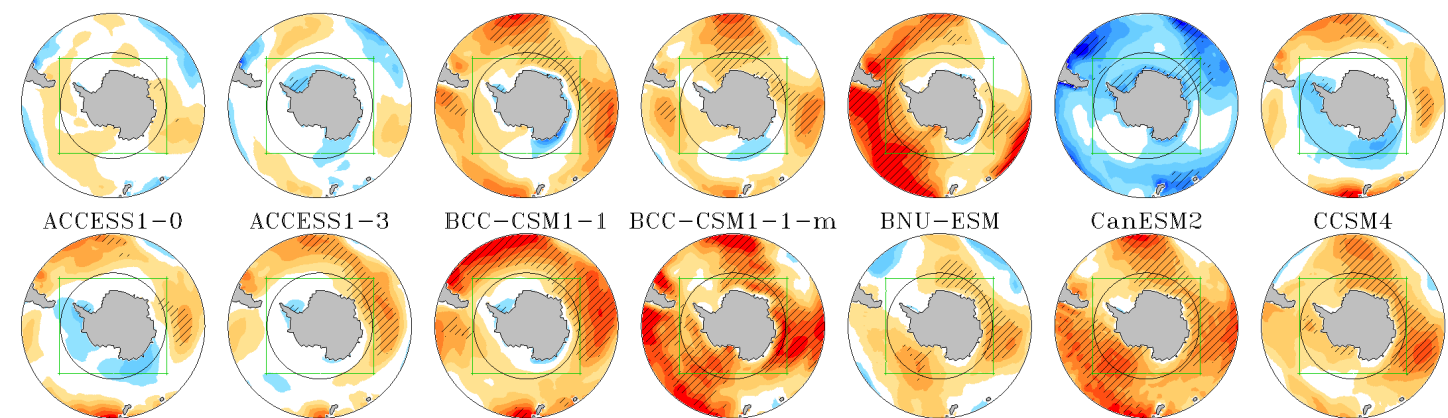

$\mathrm{CESM} \mathbb{1}-\mathrm{BGC}$
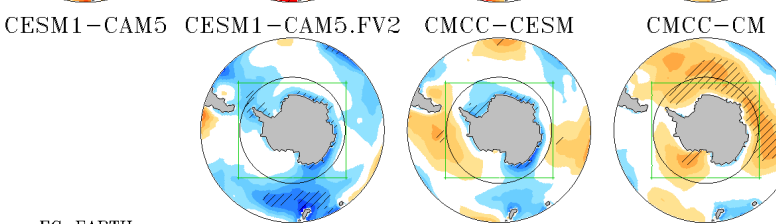

$\mathrm{CMCC}-\mathrm{CMS}$

CNRM-CM5
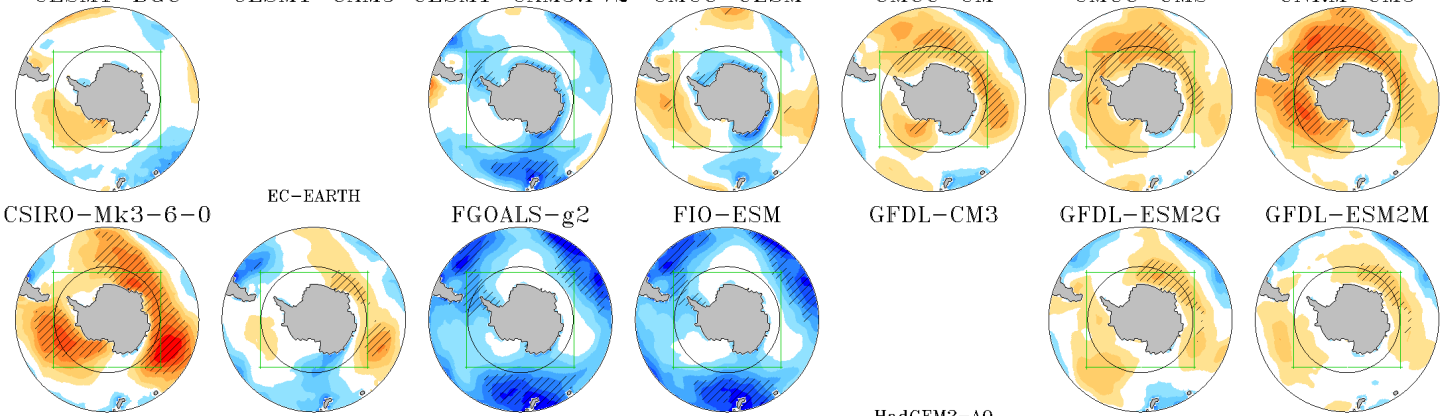

GFDL-CM3

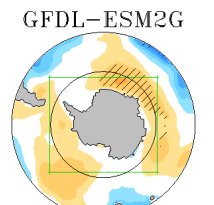

GFDL-ESM2M

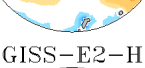

GISS-E2-H-CC
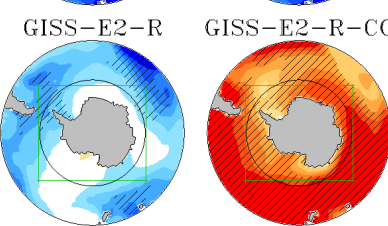

HadGEM2-A0
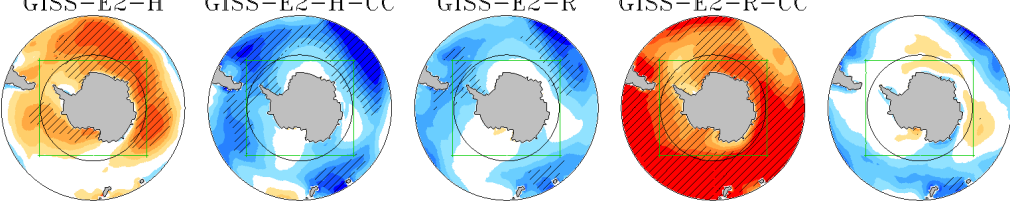

HadGEM2-CC
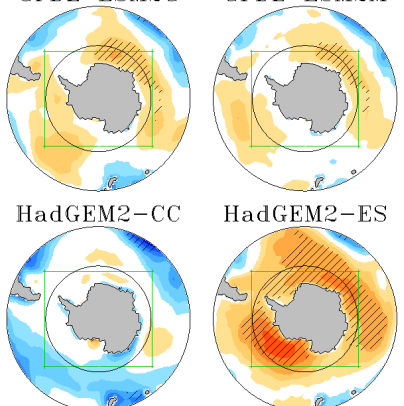

HadGEM2-ES

INM-CM4
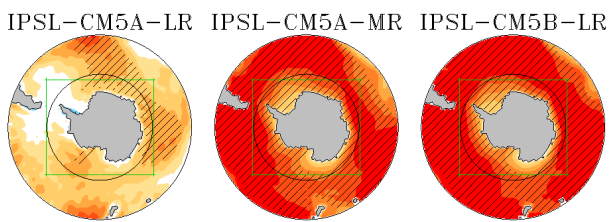

MIROC-ESM
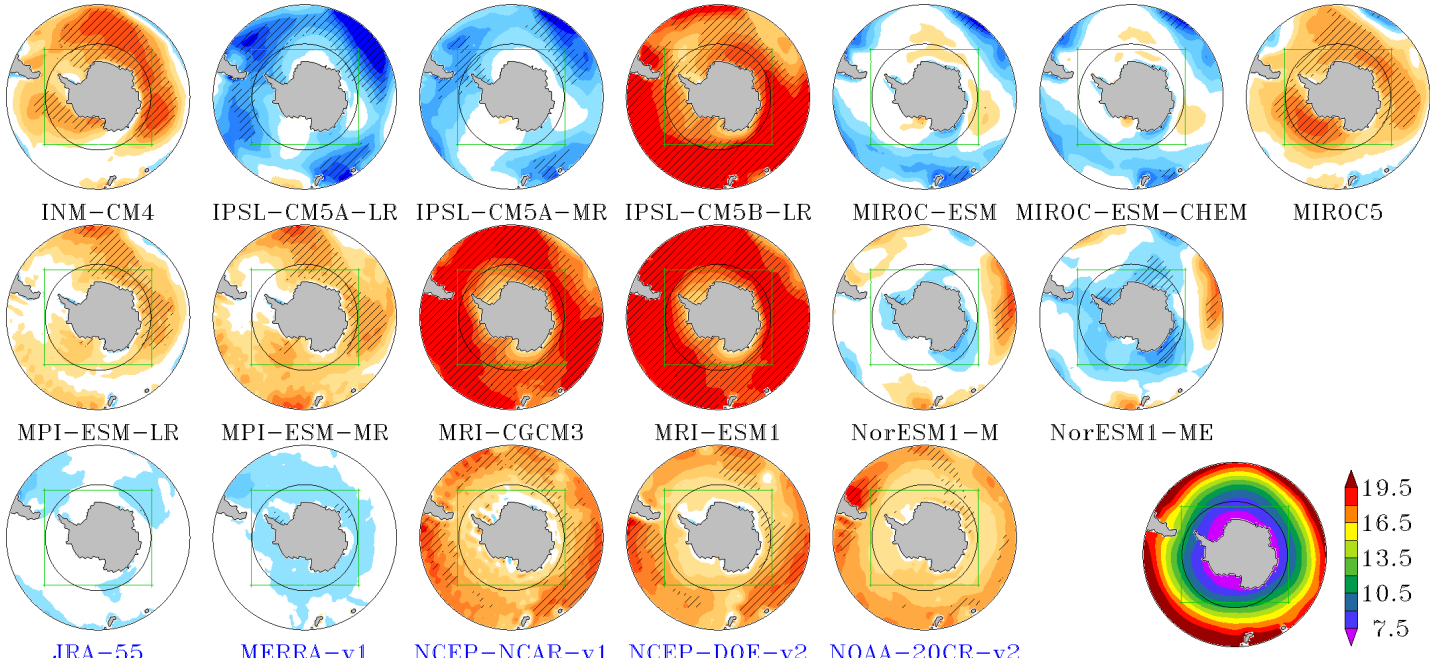

MERRA-v1

\begin{tabular}{ccccccc}
$\mathrm{NCEP}-\mathrm{NCAR}-\mathrm{v} 1$ & \multicolumn{2}{c}{$\mathrm{NCEP}-\mathrm{DOE}-\mathrm{v} 2$} & \multicolumn{2}{c}{$\mathrm{NOAA}-20 \mathrm{CR}-\mathrm{v} 2$} \\
\hline-2.5 & -1.5 & -0.5 & 0.5 & 1.5 & 2.5
\end{tabular}

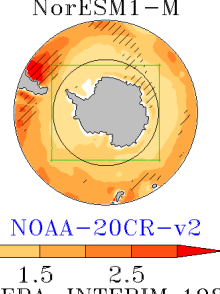

NorESM1-ME

Summer precipitable water error in respect to ERA-INTERIM $1980-2004(\mathrm{~kg} / \mathrm{m} 2)$

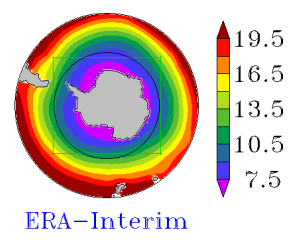

Figure S4: Same as Fig. 1 but for summer precipitable water (in $\mathrm{kg} \mathrm{m}^{-2}$ ). 

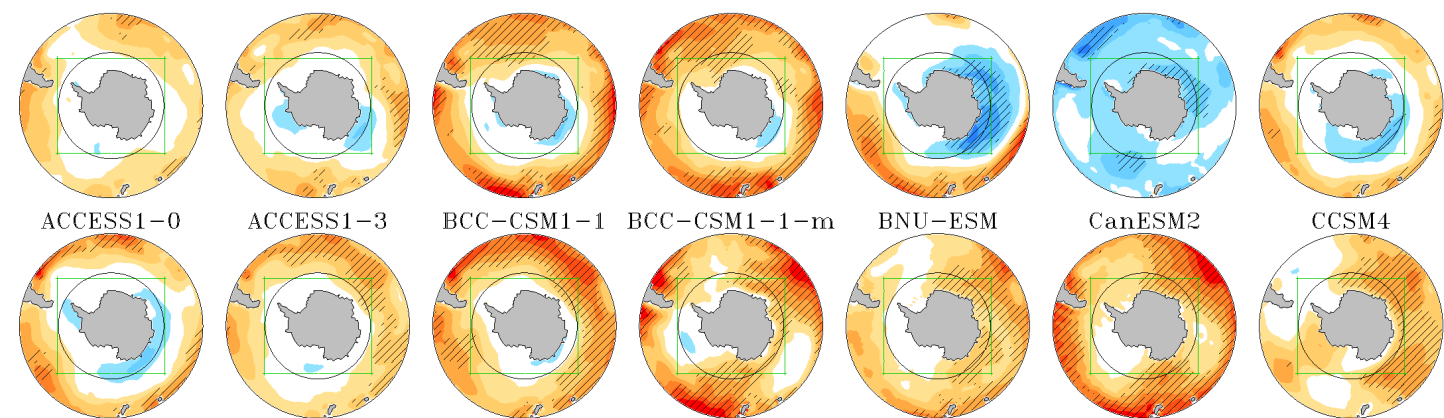

BCC-CSM1-1 BCC-CSM 1-1-m
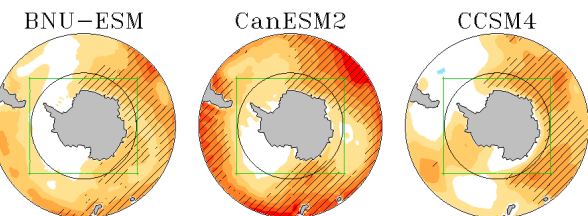

$\mathrm{CESM} \mathbb{1}-\mathrm{BGC}$
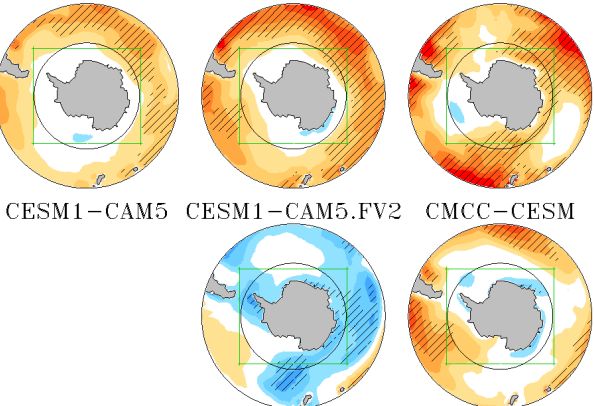

CMCC-CESM
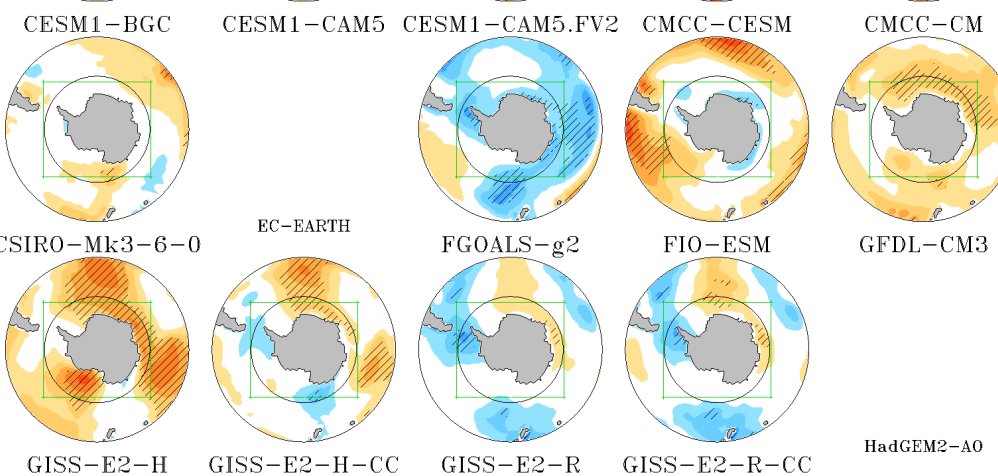

CMCC-CMS

CNRM-CM5
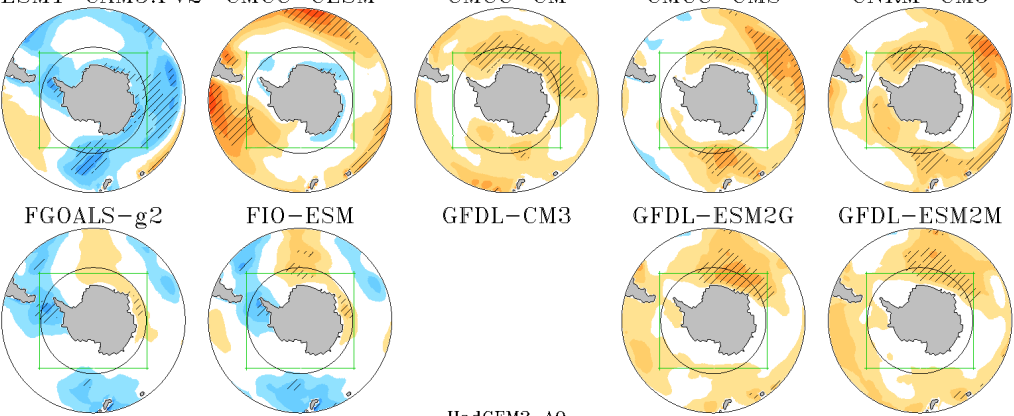

GFDL-CM3
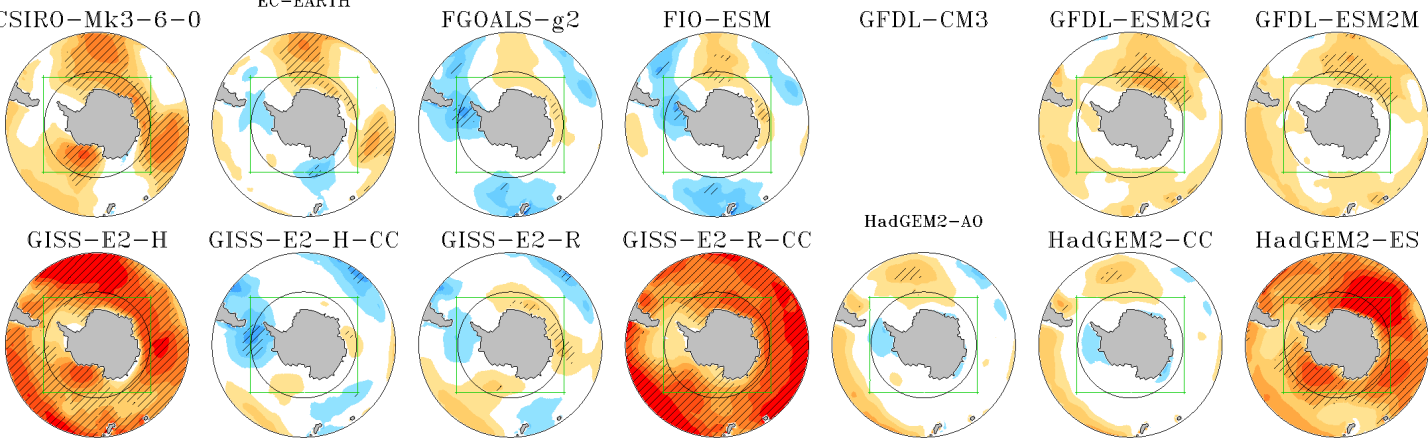

GISS-E2-R-CC

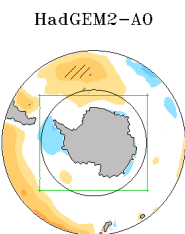

HadGEM2-CC

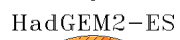

INM-CM 4
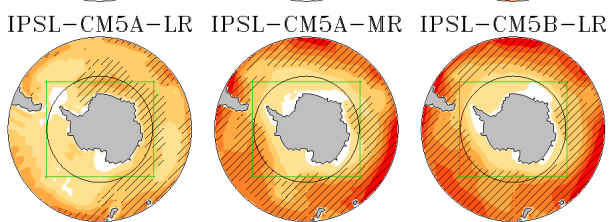

MIROC-ESM MIROC-ESM-CHEM
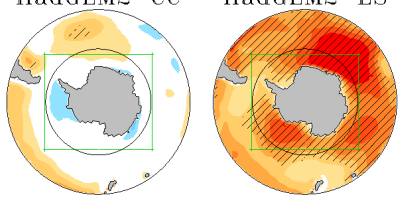

MIROC5
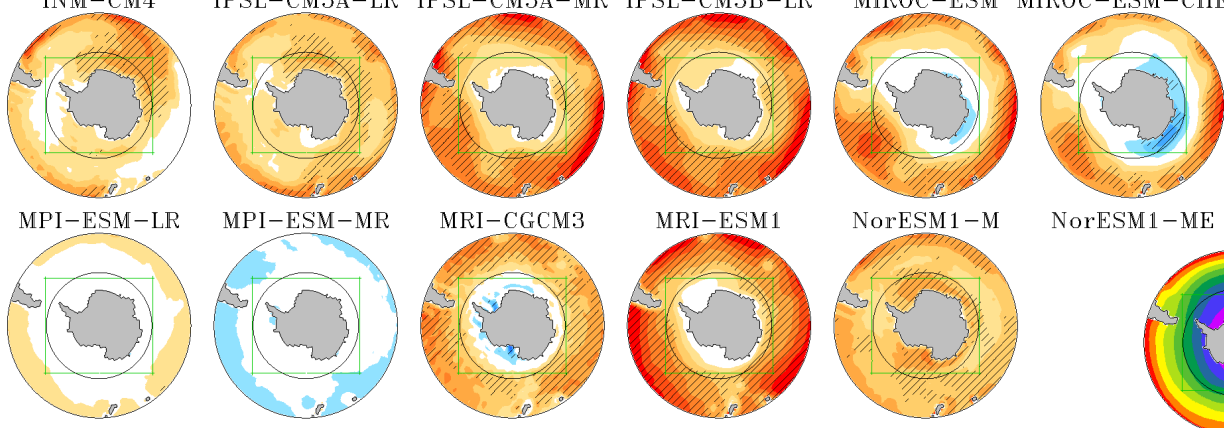

NorESM 1-M

NorESM1-ME

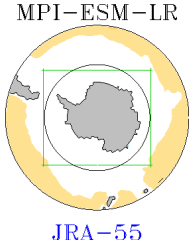

MERRA-v1

\begin{tabular}{cccccc}
$\mathrm{NCEP}-\mathrm{NCAR}-\mathrm{v} 1$ & \multicolumn{2}{c}{$\mathrm{NCEP}-\mathrm{DOE}-\mathrm{v2}$} & \multicolumn{2}{c}{$\mathrm{NOAA}-20 \mathrm{CR}-\mathrm{v} 2$} \\
\hline-2.5 & -1.5 & -0.5 & 0.5 & 1.5 & 2.5
\end{tabular}

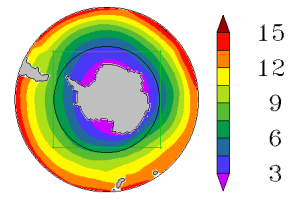

ERA-Interim

Winter precipitable water error in respect to ERA-INTERIM $1980-2004(\mathrm{~kg} / \mathrm{m} 2)$

Figure S5: Same as Fig. 1 but for winter precipitable water $\left(\right.$ in $\mathrm{kg} \mathrm{m}^{-2}$ ). 

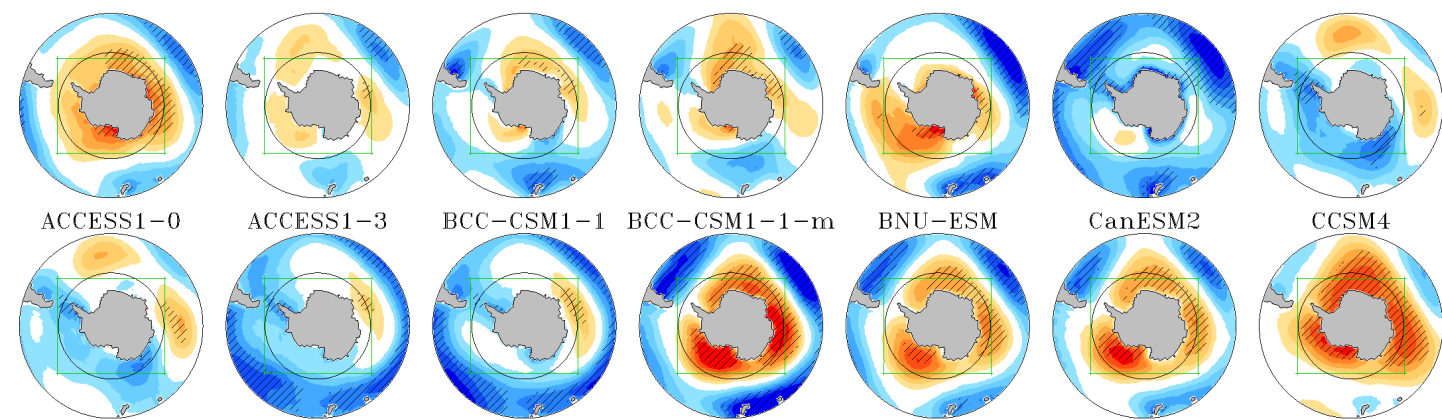

$\operatorname{CCSM} 4$

CESM1-BGC
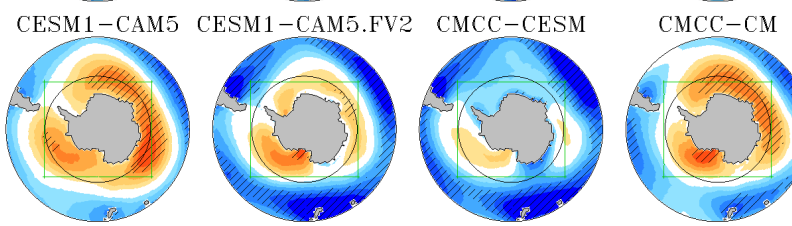

$\mathrm{CMCC}-\mathrm{CMS}$
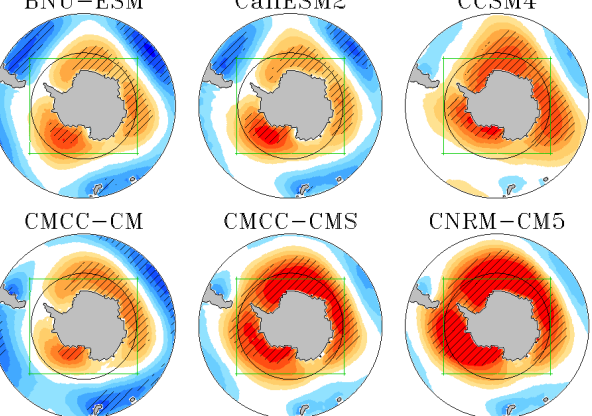

CNRM-CM5
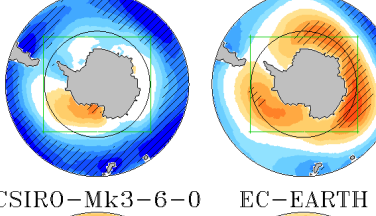

FGOALS-g2

FIO-ESM
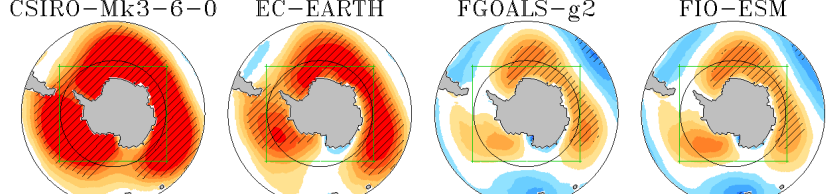

GFDL-CM3
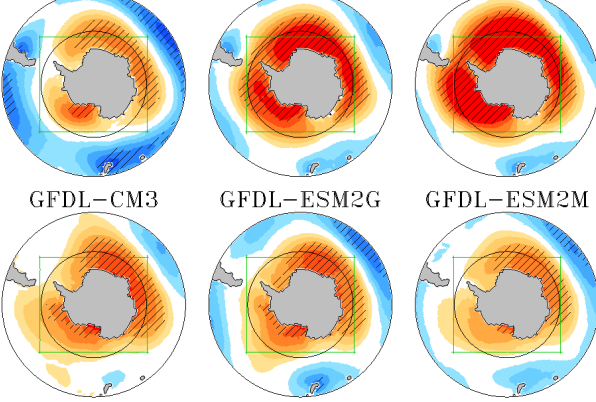

GFDL-ESM2M
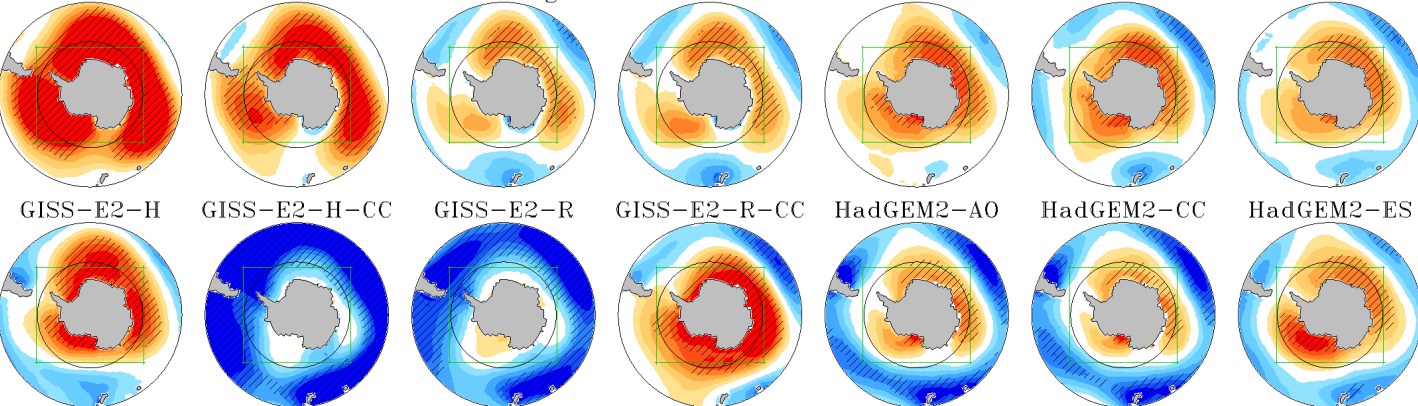

HadGEM2-ES

INM-CM4
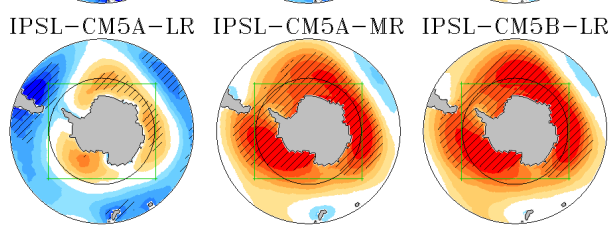

MIROC-ESM
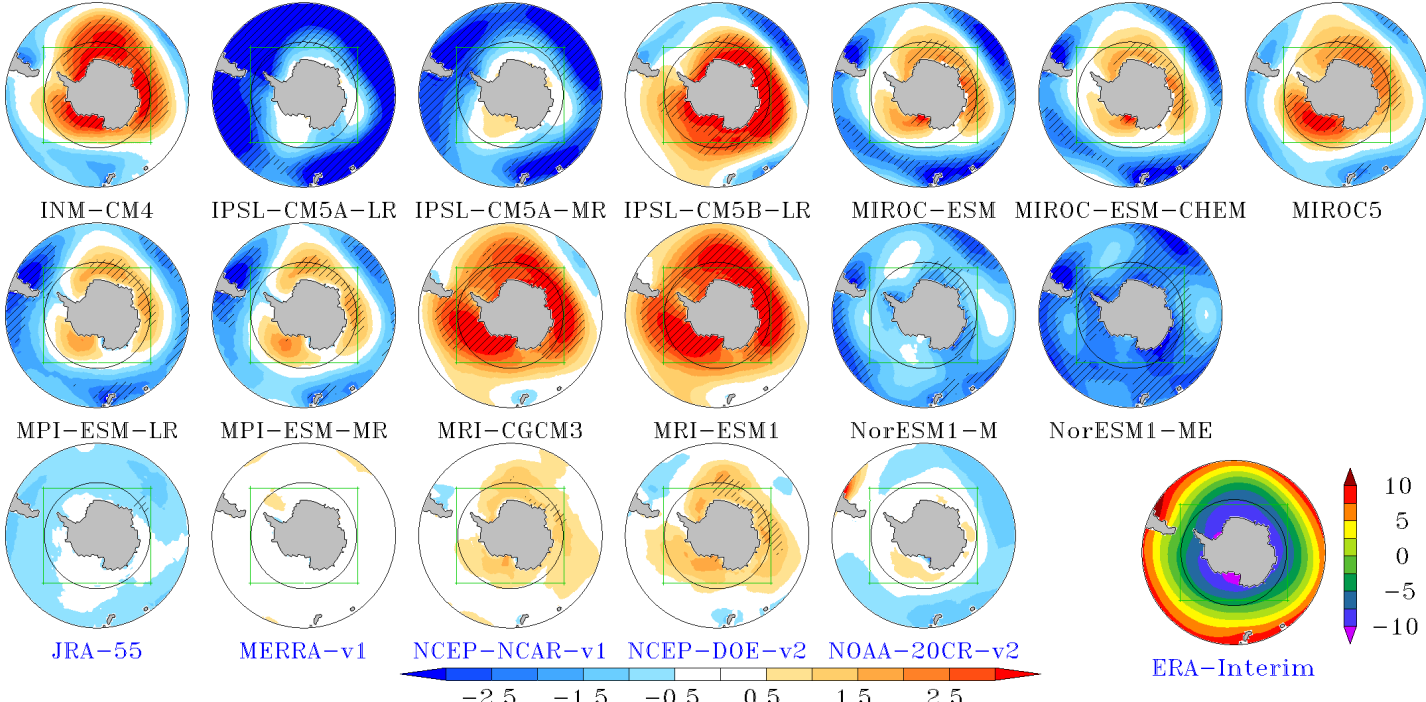

NorESM1-ME

Summer $850 \mathrm{hPa}$ temperature error in respect to ERA-INTERIM $1980-2004\left({ }^{\circ} \mathrm{C}\right)$

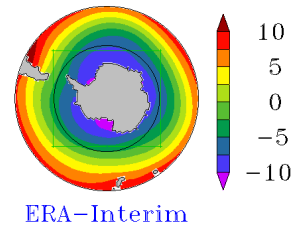

Figure S6: Same as Fig. 1 but for summer air temperature at $850 \mathrm{hPa}\left(\right.$ in ${ }^{\circ} \mathrm{C}$ ). 

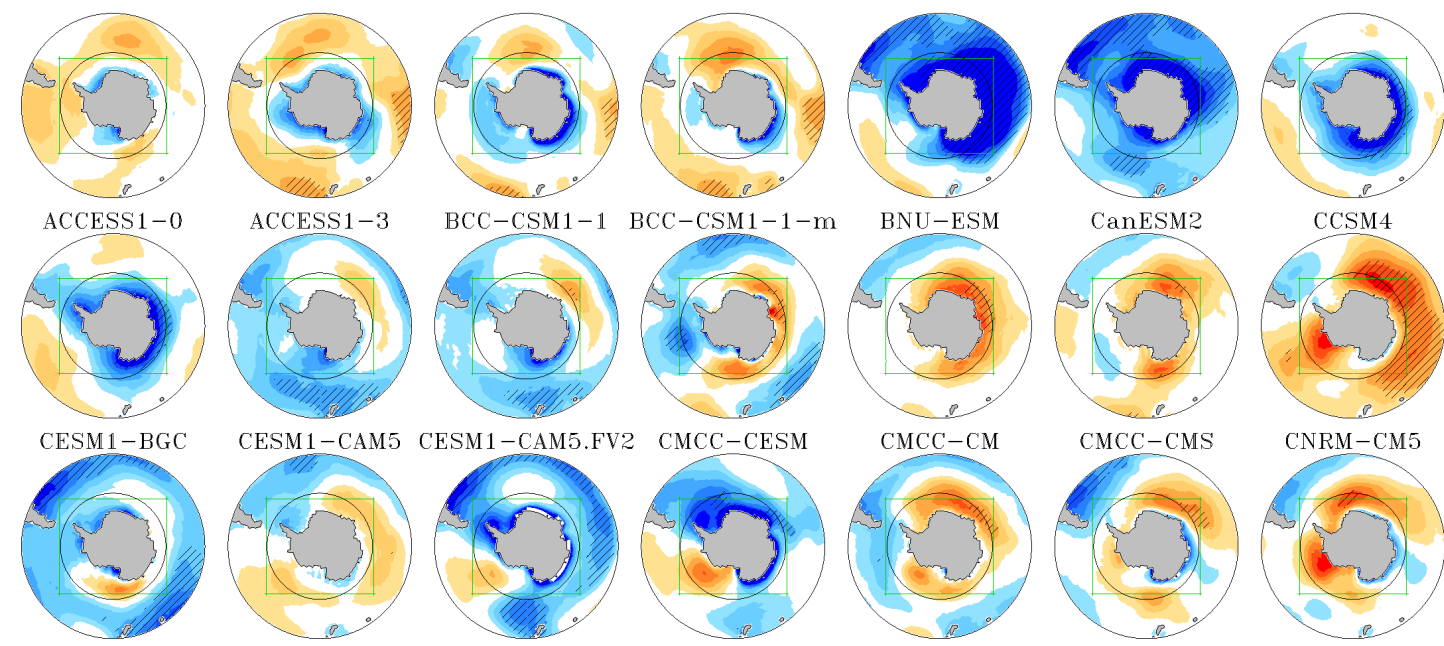

$\mathrm{BCC}-\mathrm{CSM} 1-1 \quad \mathrm{BCC}-\mathrm{CSM} 1-1-\mathrm{m}$
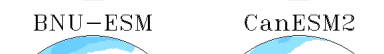

CCSM 4
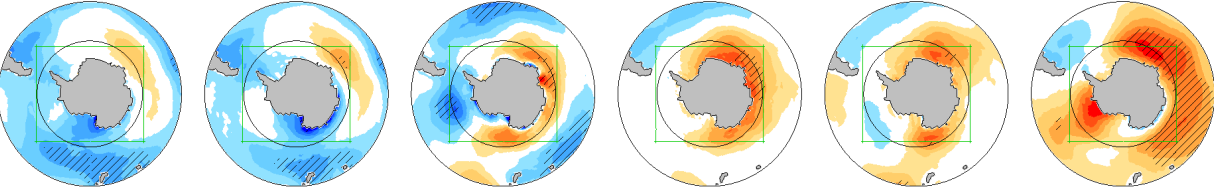

CESM1-CAM5 CESM1-CAM5.FV2 CMCC-CESM
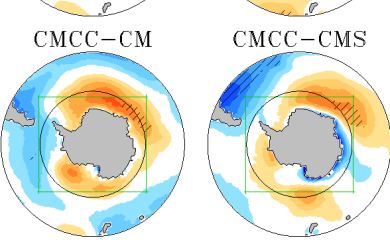

CNRM-CM5
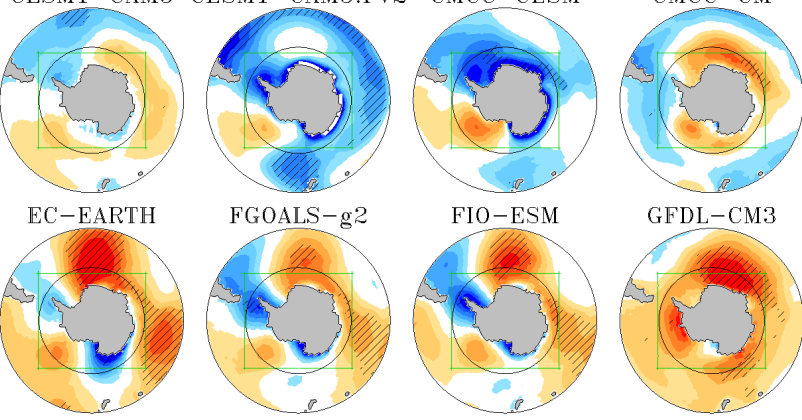

GFDL-CM3
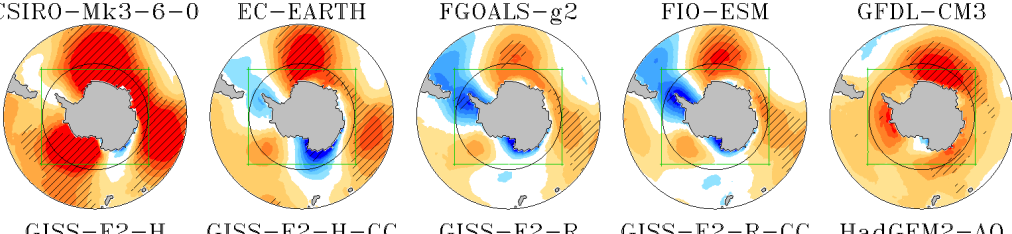

GFDL-ESM2G
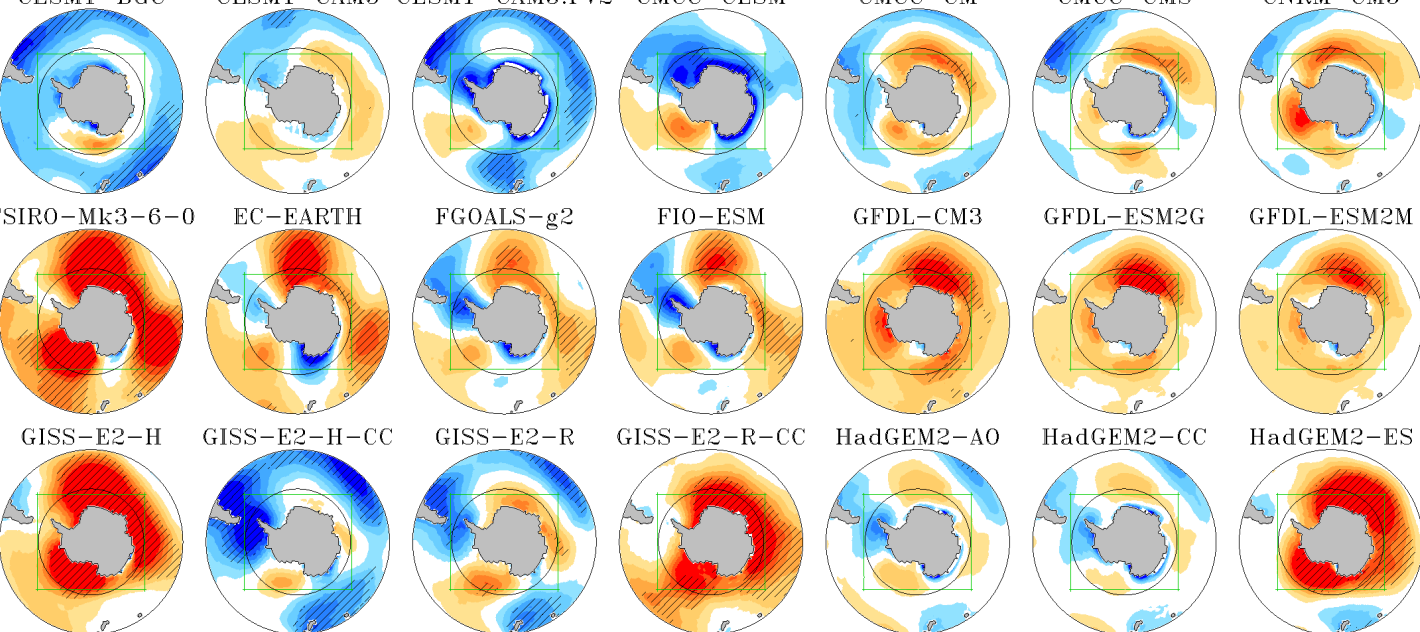

INM-CM4
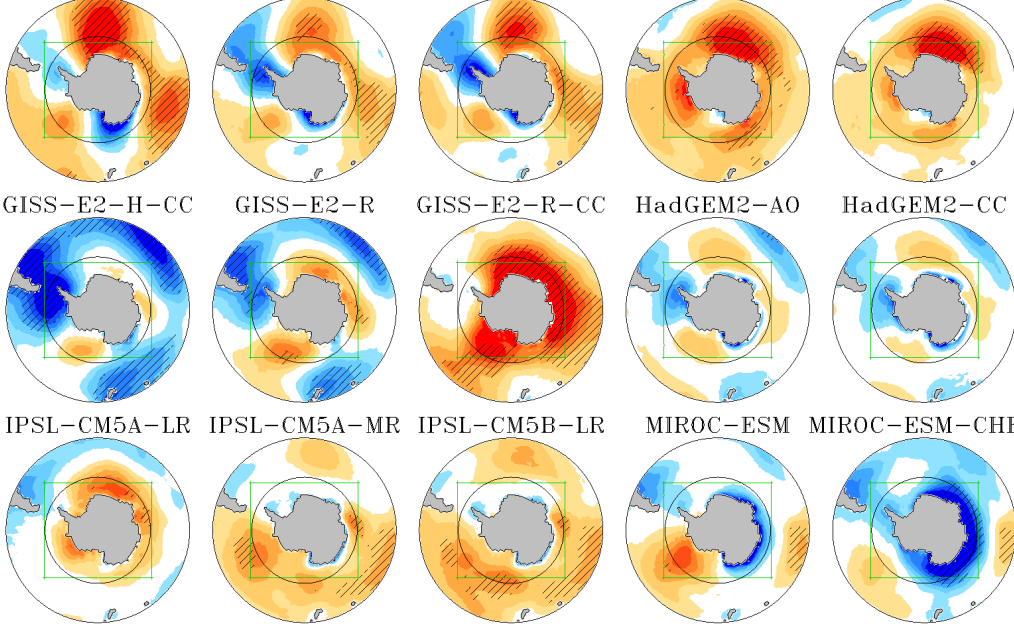

GFDL-ESM2M
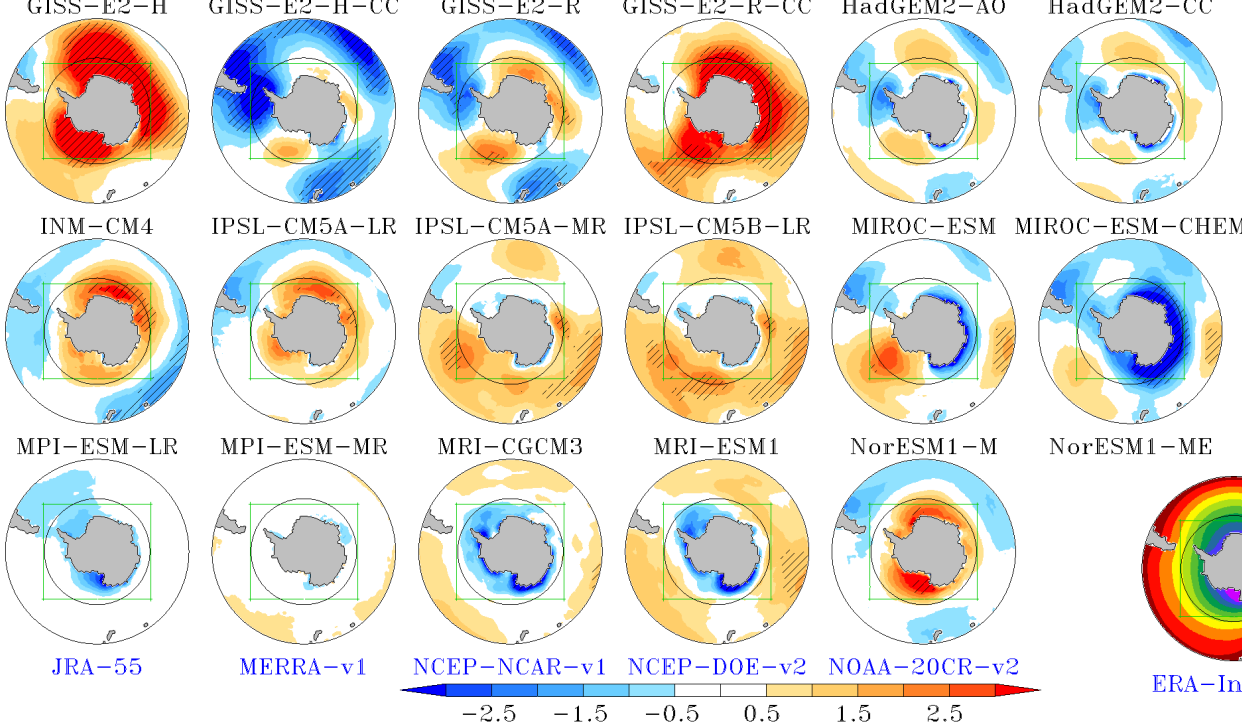

MIROC-ESM MIROC-ESM-CHEM
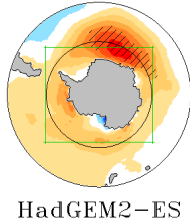

MPI-ESM-LR

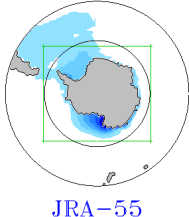

MERRA-v1
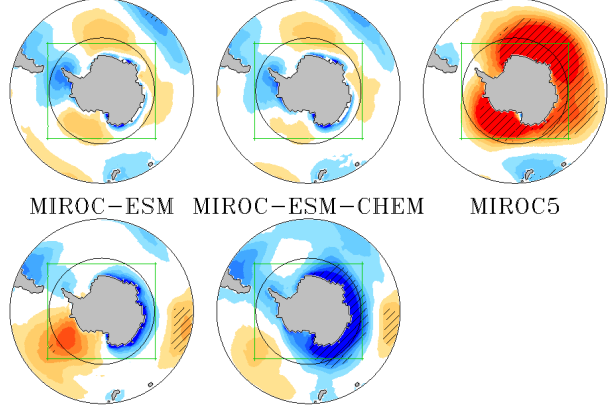

MIROC5

Winter $850 \mathrm{hPa}$ temperature error in respect to ERA-INTERIM $1980-2004\left({ }^{\circ} \mathrm{C}\right)$

Figure S7: Same as Fig. 1 but for winter air temperature at $850 \mathrm{hPa}\left(\right.$ in $\left.{ }^{\circ} \mathrm{C}\right)$. 

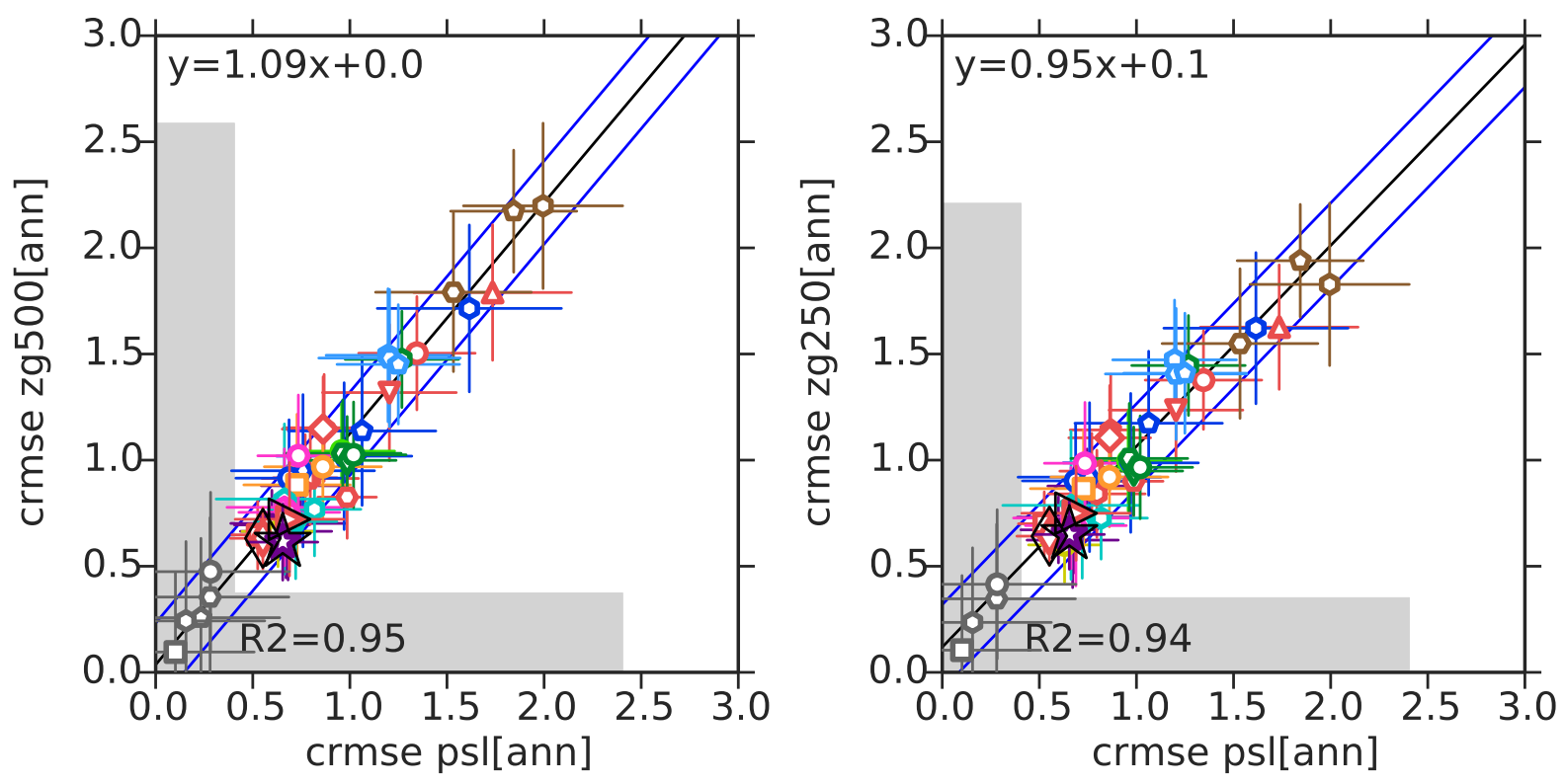

Figure S8: The spatial centered rmse (crmse) is computed for 1980-2010 mean values of models vs. ERA-Interim and scaled by spatially-averaged standard deviation of ERA-Interim annual values. Here we compare annual geopotential heights at $500 \mathrm{hPa}$ (zg500[ann], left) and at 250hPa (zg250[ann], right) without masking ice-sheet areas to annual sea-level pressure over the ocean (psl[ann], X-axis). See Fig. 3 for chart details. 

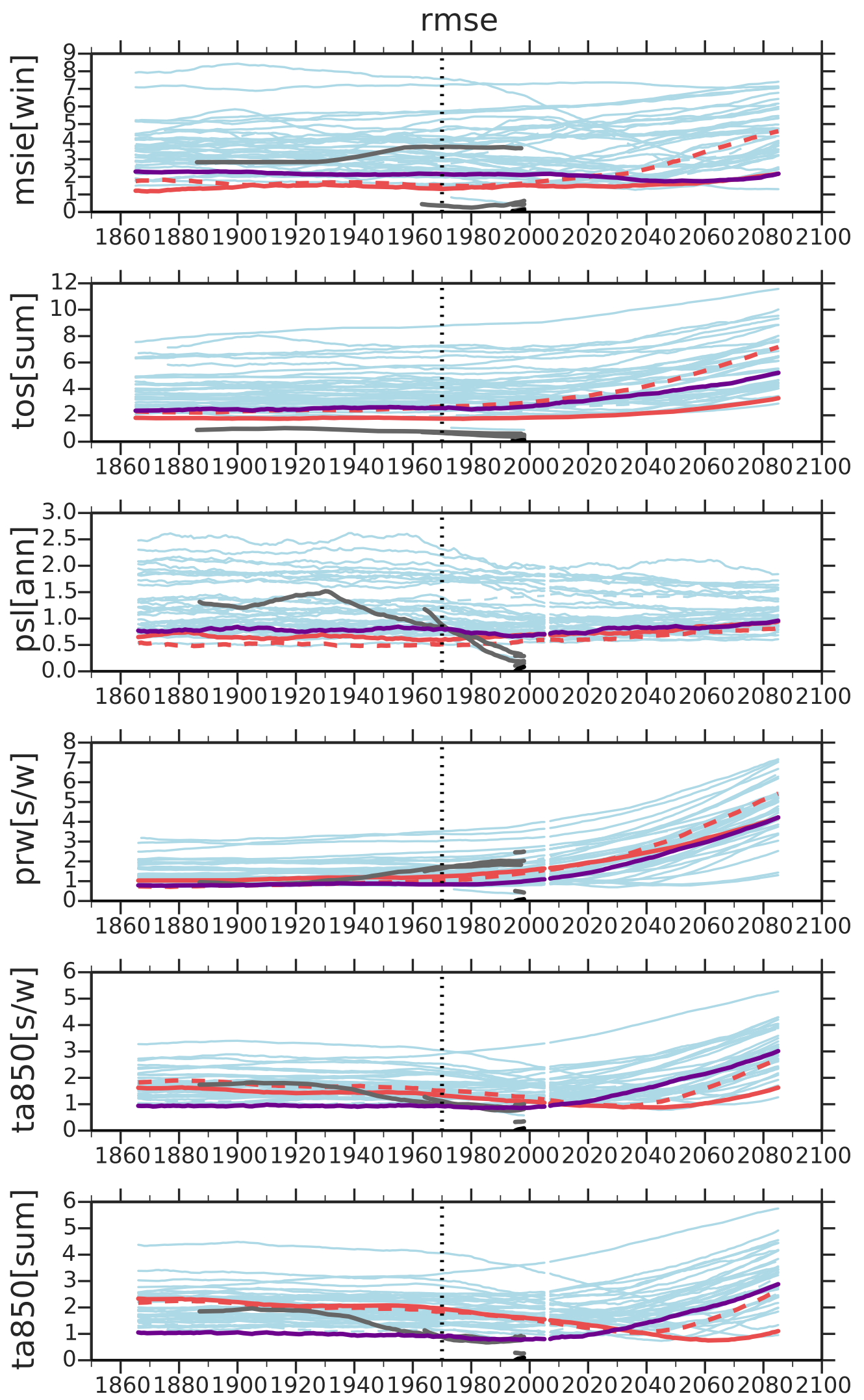

Figure S9: 31-years time-averages running CPIs between 1950 and 2100. The field of reference is ERA-Interim for the period 1980-2010. Thin light blue lines are for the 41 CMIP5 GCMs (historical+RCP85) and thick dark grey lines are for the reanalyses. Three GCMs are highlighted with thick colored lines: ACCESS1-3 in purple, CESM1-CAM5 in dashed red and NorESM1-M in solid red. Each point of a line is the central year of the 31-year period. 


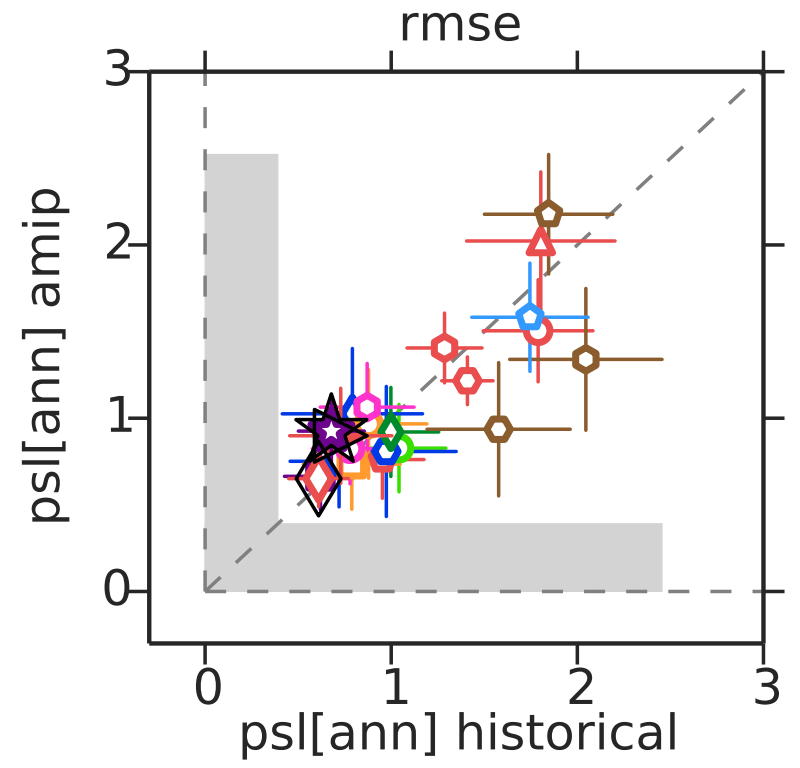

口 ACCESS1-0

^ ACCESS1-3

- BCC-CSM1-1

- BCC-CSM1-1-m

- BNU-ESM

- CCSM4

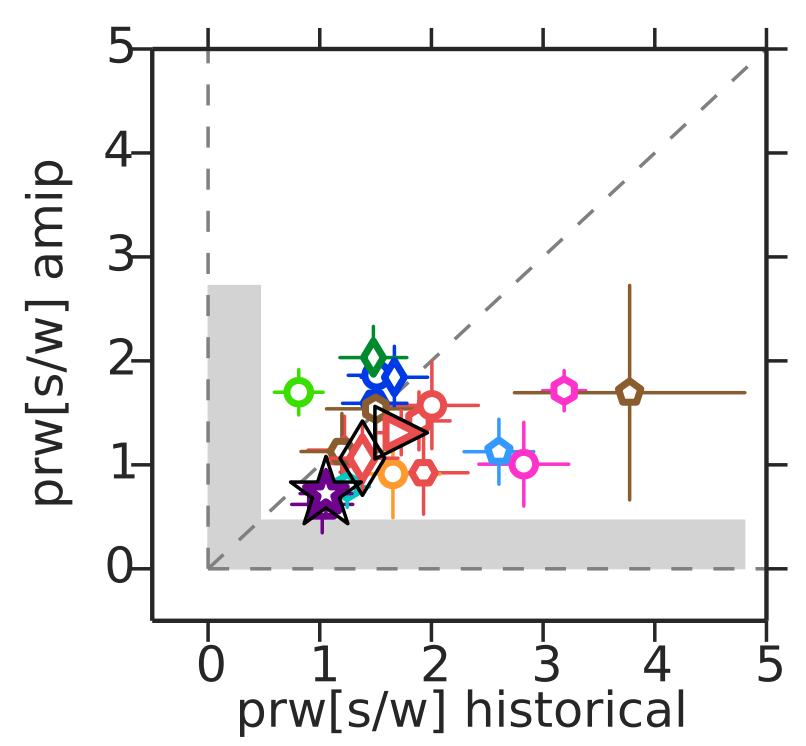

$\checkmark$ CESM1-CAM5

$\triangle$ FGOALS-g2

$\triangle$ NorESM1-M

- CSIRO-Mk3-6-0

- CMCC-CM

- MPI-ESM-LR

$\checkmark$ MPI-ESM-MR

- CNRM-CM5

口 EC-EARTH

- GFDL-CM3

$\checkmark$ GISS-E2-R

- INM-CM4

- MRI-CGCM3

- IPSL-CM5A-LR

- IPSL-CM5A-MR

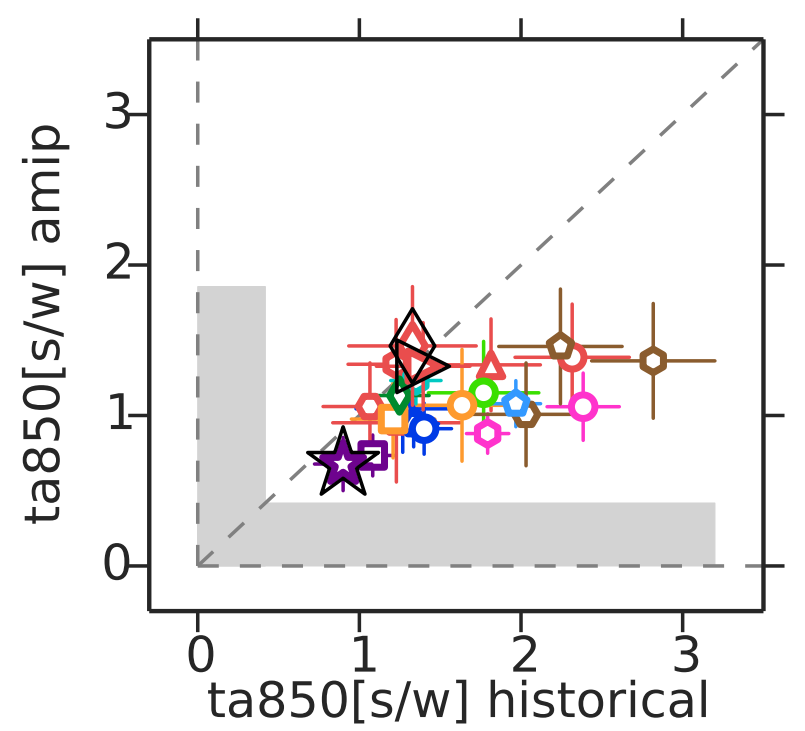

- IPSL-CM5B-LR

- MIROC5

Figure S10: Comparison of Amip (y-axis) versus Historical (x-axis) for the six selected metrics. For Amip, the averaged period is 1980-2008 (29 years) whereas for ERA-Interim and Historical runs the averaged period is 1980-2010 (31 years). See Fig. 3 for chart details. 